\title{
Thermodynamics of liquid Cu-Sn alloys
}

\author{
(*S.K. Chatterjee, L.C. Prasad) \\ *Dept. of Chemistry, M.M.A.M. Campus, Biratnagar.
}

\section{Abstract}

The large deviation from the ideal mixture behavior and concentration dependent asymmetry in the thermodynamic properties of $\mathrm{Cu}_{3} \mathrm{Sn}$ liquid alloys is investigated within a simple theoretical model of heterocoordination (i.e. a model in which there is a preference for unlike atoms pairing as nearest neighbors). The analysis suggest that hetero coordination leading to the formation of chemical complexes $\mathrm{Cu}_{3} \mathrm{Sn}$ is likely to exist in the melt but is only of a weakly interacting nature. The system exhibits almost ideal behavior at Sn-rich end.

\section{Introduction}

It has been of considerable interest to theoreticians to explain the concentration dependent asymmetry of the properties of mixing of binary liquid alloys.

Various compound formation model ${ }^{1-5}$ are being used by the theoreticians to understand the alloying behaviour of compound forming alloys, which signifies the importance of hetero coordination leading to unlike atoms pairing as a prime reason for compound formation.

Phase diagrams which are the fundamental sources of information on alloy system attribute the presence of intermetallic compounds in the solid form a6 one or more stoichiometruc composition, led the theoreticians to believe in the existence of chemical complexes near the melting temperature of binary molten alloys.

$$
\text { XS XS }
$$

In $\mathrm{Cu}$-Sn binary liquid alloys though, $\mathrm{G}_{\mathrm{M}} \mathrm{n}$ not very large $\left(\mathrm{G}_{\mathrm{M}}=-6.25 \mathrm{Kj}\right)$. Phase diagram ${ }^{6}$ manifest the presence of $\mathrm{Cu}_{3} \mathrm{Sn}$ intermediate phase in the solid state. We therefore assume the chemical complexes $\mathrm{A} \mu \mathrm{B} v(\mu \mathrm{A}+v \mathrm{~B}=\mathrm{A} \mu \mathrm{B} v$, $\mu=3, v=1, A=C u, B=S n$ ) exists in the liquid state close to the melting temperature. Thus the binary $A=B$ alloy consist of a mixture of $\mathrm{A}$ atoms, $\mathrm{B}$ atoms and a number of chemical complexes $\mathrm{A} \mu \mathrm{B} v$ all in chemical equilibrium with one another.

The concept of complex forngtion has been successfully used in our work to investigate the asymmetry in the thermodynamic properties $\left(\mathrm{G}, \mathrm{M}, \mathrm{H}_{\mathrm{M}}, \mathrm{S}_{\mathrm{M}}\right)$ of CuSn liquid alloys

Theoretical formalism has been discussed in section 2, while section 3 deals with numerical results and discussion, conclusion in provided in section 4.

\section{Theory}

A binary alloy contains in all $\mathrm{N}_{A}\left(=\mathrm{C}_{A} \mathrm{~N}\right)$ atoms of $\mathrm{A}(=\mathrm{Cu})$ and $\mathrm{N}_{\mathrm{B}}\left(\mathrm{C}_{\mathrm{B}} \mathrm{N}\right)$ atoms of $\mathrm{B}(=\mathrm{Sn})$ following $\mathrm{C}_{\mathrm{A}}+\mathrm{C}_{\mathrm{B}}=1$, $\mathrm{C}_{\mathrm{A}}=\mathrm{C}$ and $\mathrm{C}_{\mathrm{B}}=(1-\mathrm{C})$ are the atomic concentrations and ' $\mathrm{N}$ ' is the Avogadro's number. Following Bhatia and Hargrove ${ }^{3}$, it is assumed that the chemical complexes $\mathrm{Cu}_{3} \mathrm{Sn}$ exists in the molten phase. Te binary alloy then consists of ' $\mathrm{n}_{1}$ ', atom of $\mathrm{Cu}, \mathrm{n}_{2}$ atom of $\mathrm{Sn}$ and $\mathrm{n}_{3}$ complexes of $\mathrm{Cu}_{3} \mathrm{Sn}$, then from the law of conservation of atoms.

$\mathrm{n}_{1}=\mathrm{NC}-\mu \mathrm{n}_{3}$

$\mathrm{n}_{2}=\mathrm{N}(1-\mathrm{C})-\mathrm{vn}_{3}$ 


$$
\mathrm{n}=\mathrm{n}_{1}+\mathrm{n}_{2}+\mathrm{n}_{3}=\mathrm{N}-(\mu+\mathrm{v}-1) \mathrm{n}_{3}
$$

where $\mu=3$ and $v=1$ and $n$ is the total number of atoms in the case of compound formation.

The free energy of mixing $G_{M}$ is the binary alloy can be expressed as

$\mathrm{G}_{\mathrm{M}}=-\mathrm{n}_{3} \mathrm{~g}+\Delta \mathrm{G}$

Where ' $\mathrm{g}$ ' is the formation energy of the complex and the first term $\left(-\mathrm{n}_{3} \mathrm{~g}\right)$ represents the lowering of free energy due to the formation of complexes in the alloy. $\Delta \mathrm{G}$ represent the free energy of mixing of ternary mixture of fixed $\mathrm{n}_{1}, \mathrm{n}_{2}$ and $\mathrm{n}_{3}$ whose constituents $\mathrm{Cu}, \mathrm{Sn}$ and $\mathrm{Cu}_{3} \mathrm{Sn}$ assumed to interact weakly with one another.

Flory gave an expression for $\Delta \mathrm{G}$ taking account the difference of size between the unassociated species given as

$\Delta \mathrm{G}=\mathrm{RT}\left[\sum_{\mathrm{i}=1}^{3} \mathrm{n}_{\mathrm{i}} \ln \left(\frac{\mathrm{ni}}{\mathrm{N}}\right)+\mathrm{n}_{3} \ln \left\{\frac{(\mu+\mathrm{v}) \mathrm{n}_{3}}{\mathrm{~N}}\right\}+\sum_{\mathrm{i}} \sum_{<\mathrm{J}}\left\{\left(\frac{\mathrm{n}_{\mathrm{i}} \mathrm{n}_{\mathrm{J}}}{\mathrm{N}}\right) \frac{\mathrm{V}_{\mathrm{ij}}}{\mathrm{RT}}\right\}\right]$

Where, $\mathrm{V}_{\mathrm{ij}}(\mathrm{i}, \mathrm{j}=1,2,3)$ are the interaction energy through which the left over $\mathrm{A}(\equiv \mathrm{Cu}), \mathrm{B}(=\mathrm{Sn})$ and $\mathrm{AB}\left(=\mathrm{Cu}_{3} \mathrm{Sn}\right)$ interact with one another. $\mathrm{V}_{\mathrm{ij}}$ are independent of concentration but may depend on temperature. Using equation (2) and (3) $\mathrm{G}_{\mathrm{M}}$ can be rewritten as

$\mathrm{G}_{\mathrm{M}}=-\mathrm{n}_{3 \mathrm{~g}}+\mathrm{RT}\left[\sum_{\mathrm{i}=1}^{2} \mathrm{n}_{\mathrm{i}} \ln \left(\frac{\mathrm{ni}}{\mathrm{N}}\right)+\mathrm{n}_{3}\left\{\ln (\mu+\mathrm{v}) \frac{\mathrm{n}_{3}}{\mathrm{~N}}\right\}+\sum \sum\left(\frac{\mathrm{n}_{\mathrm{i}} \mathrm{n}_{\mathrm{J}}}{\mathrm{N}}\right) \frac{\mathrm{V}_{\mathrm{ij}}}{\mathrm{RT}}\right]$

The equilibrium values of $\mathrm{n}_{3}$ can be obtained via the condition $\left.\left[\frac{\partial \mathrm{G}_{\mathrm{M}}}{\partial \mathrm{n}_{3}}\right]\right]_{T, P, C, N}=0$

Equation (4) and (5) given,

$n_{1} n_{1}^{\mu} n_{2}^{v}=n_{3} N^{\mu+v-1}(\mu+v) \exp \left[-(\mu+v-1)-\left(\frac{g}{R T}\right)+Y\right]$

Where $Y=\left(\frac{\mathrm{g}}{\mathrm{RT}}\right)^{-1}\left[\left(\mathrm{n}_{1}-\mu \mathrm{n}_{3}\right) v_{13}+\left(\mathrm{n}_{2}-\mu \mathrm{n}_{3}\right) \mathrm{v}_{13}-\left(\mu \mathrm{n}_{2}+v \mathrm{n}_{1}\right) \mathrm{v}_{12}\right]$

Once the expression for $G_{M}$ obtained, other thermodynamic function, which are related to $G_{M}$, through standard thermodynamic relation follows readily.

$\mathrm{H}_{\mathrm{M}}=\mathrm{G}_{\mathrm{M}}-\mathrm{T}\left(\frac{\partial \mathrm{G}_{\mathrm{M}}}{\partial \mathrm{T}}\right)$ T.P.N

$\mathrm{S}_{\mathrm{M}}=\left(\frac{\mathrm{H}_{\mathrm{M}}-\mathrm{G}_{\mathrm{M}}}{\mathrm{T}}\right)$

When equation (4) is used in equation (8), the expression for $\mathrm{H}_{\mathrm{M}}$ and $\mathrm{S}_{\mathrm{M}}$ obtained as

$\mathrm{H}_{\mathrm{M}}=-\mathrm{n}_{3} \mathrm{~g}+\mathrm{n}_{3} \mathrm{~T}\left(\frac{\partial \mathrm{g}}{\partial \mathrm{T}}\right) \mathrm{p}+\sum \sum\left(\frac{\mathrm{n}_{\mathrm{i}} \mathrm{n}_{\mathrm{j}}}{\mathrm{N}}\right)\left[\mathrm{v}_{\mathrm{ij}}-\mathrm{T}\left(\frac{\partial \mathrm{v}_{\mathrm{ij}}}{\partial \mathrm{T}}\right) \mathrm{p}\right]$

$\mathrm{S}_{\mathrm{M}}=-\mathrm{n}\left(\frac{\partial \mathrm{g}}{\partial \mathrm{T}}\right) \mathrm{p}-\mathrm{R}\left[\mathrm{n}_{1} \ln \mathrm{n}_{1}+\mathrm{n}_{2} \ln \mathrm{n}_{2}+\mathrm{n}_{3} \ln \left\{(\mu+\mathrm{v}) \mathrm{n}_{3}\right\}\right]-\sum \sum \mathrm{n}_{\mathrm{i}} \mathrm{n}_{\mathrm{j}}\left(\frac{\partial \mathrm{V}_{\mathrm{ij}}}{\partial \mathrm{T}}\right) \mathrm{p}$

\section{Results and discussion}

\subsection{Excess free energy of mixing}

Excess free energy of mixing G ${ }_{\mathrm{XS}}$ of $\mathrm{CuSn}$ system at $1400^{\circ} \mathrm{K}$ can be computed using equation (4). The basic imputes for the calculation are $n_{2}$,g and $\mathrm{V}_{\mathrm{ij}}$, Equilibrium relation ${ }^{6}$ which involves $g$ and $\mathrm{V}_{\mathrm{ij}}$ are used to calculation $\mathrm{n}_{3}$. The interaction energies $\mathrm{V}_{\mathrm{ij}}$ and $\mathrm{g}$ are determined following the method suggested by Bhatia and Nargrove ${ }^{3}$.

The values of $g$ and $V_{i j}$ were adjusted to obtain the concentration dependence of $G_{M}$ or $G_{M}^{X S}$ is obtained.

The values of interaction energy parametes are choosen as follows.

$$
\frac{\mathrm{g}}{\mathrm{RT}}=1.5, \frac{\mathrm{V}_{12}}{\mathrm{RT}}=-0.6, \frac{\mathrm{V}_{13}}{\mathrm{RT}}=0.5, \frac{\mathrm{V}_{213}}{\mathrm{RT}}=-0.5 \text {. } \rightarrow
$$

The above set of energy parameters are utilized in equation (6) to obtain $n_{3}$. The quantity $n_{1}$ and $n_{2}$ can be obtained by substitution $\mathrm{n}_{3}$ equation. (1). 
The concentration dependence of $\mathrm{G}_{\mathrm{M}}$ is fig (1).

Fig (1) shows a reasonable agreement between the computed and experimental value of $\mathrm{G}_{\mathrm{M}}^{\mathrm{XS}}$ except a slight deviation in the concentration range $0.7 \leq \mathrm{C}_{\mathrm{cu}} \leq 0.9$. The values are found negative at all concentrations and being minimum around $\mathrm{C}_{\mathrm{cu}}=0.7$, which is close to the compound forming concentration $\mathrm{C}_{\mathrm{cu}}=0.75\left(\mathrm{C}_{\mathrm{c}}=\right.$ compound forming concentrations $=\mu / \mu+v)$. The figure also exhibits asymmetry around equi-atomic concentration.

3.2 Heat of mixing and Entropy of mixing Equations (9) and (10) have been used to evaluate $\mathrm{H}_{\mathrm{M}}$ and $\mathrm{S}_{\mathrm{M}}$ respectively. The temperature and energy parameter equation (11) are same. In addition to energy parameters their temperature derivative $\partial \mathrm{g} / \partial \mathrm{T}$ and $\partial \mathrm{v}_{\mathrm{ij}} / \partial \mathrm{T}$ are ascertained by using the observed values of $\mathrm{H}_{\mathrm{M}}$ in quuation (9). These are given as $\partial \mathrm{g} / \partial \mathrm{T}=-2.0, \partial \mathrm{v}_{12} / \partial \mathrm{T}=-3.0, \partial v_{13} / \partial \mathrm{T}=0.5, \partial v_{13} / \partial \mathrm{T}=-8.5$

Computed values of $\mathrm{H}_{\mathrm{M}}$ and $\mathrm{S}_{\mathrm{M}}$ along with experimental values are plotted in fig (2) and (3) as a function of concentration, Fig (2) shows a good agreement between the computed and experimental values of $\mathrm{H}_{M}$ except a slight deviation in magnitude in the concentration range $0.8 \leq \mathrm{C}_{\mathrm{cu}}>1.0$ The minimum value of $\mathrm{H}_{\mathrm{M}}(-0.319 \mathrm{RT})$ is observed around $\mathrm{C}_{\mathrm{cu}}=0.75$ Which is the compound forming concentration. The fig (2) also exhibits clear asymmetry around the equiatomic concentration.

Fig (3) shows a good agreement betbeen calculated and observed values of $\mathrm{S}_{\mathrm{M}}$. The values are positive at all concentrations, which shows atomic order. The $\mathrm{S}_{\mathrm{M}} \mathrm{V}_{\mathrm{s}} \mathrm{C}_{\mathrm{cu}}$ curve is found asymmetric at equiatomic concentration, $\mathrm{C}_{\mathrm{cu}}=$ 0.5 .

\section{Conclusion}

Our theoretical model which assumes the existence of $\mathrm{Cu}_{3} \mathrm{Sn}$ compound in $\mathrm{CuSn}$ molten alloys explain the concentration dependence asymmetry of mixing properties satisfactorily.

Our computed result suggest that the tendency of unlike atoms pairing ${ }^{7-10}$ depends very much on concentration. Maxmum hetero coordination occurs about $\mathrm{C}_{\mathrm{cu}}=0.75$.

\section{Acknoldegement}

We are grateful to Prof. R.N. Singh presently at Dept. of Physics, Sultan Quaboos Univ, Muscat, OMAN) for his valuable suggestions and discussions.

\section{Reference:}

1. A. B. Bhatia and W.H. Hergrove Phys Rev. 1974, B10. 316.

2. R. N. Singh Can J. Phys, 1987, 65, 309.

3. A. B. Bhatia, W.H. Hargrove and Thornton D.E. Phys Re, 1974, B9, 435.

4. L.C. Prasad, R. N. Singh, V.N. Singh, and S. K. Chatterjee : Physics 1995,B215,225

5. L.C. Prasad, S.K. Chatterjee and V.N Singh: Physics, 1996,B217-291

6. R. Hultgren, D.P. Desai, D.T. Hawkins, M. Gleiser and K.K Kelly: selected values of the thermodynamic properties of binary alloys, Metal Park; ASM, OH, 1973.

7. L.C. Prasad, R.N. Singh : Phys. Chem, Liq 1990, 22:1

8. K. Hashino and W.H. Young : J. Phy, 1980, F 10, 1364.

9. N.K.P. Singh, R.N. Singh and R.B. Choudhary: J. Phys. condense matter. 1991, 3, 3635.

10. R.N. Singh, F. Sommer : J. Phys condense matter, 1992, 4, 5345.

11. P.J. Flory : J. Chem. Phys, 1942, 10, 51. 
J. Nepal Chem. Soc., Vol. 21, 2006

XS

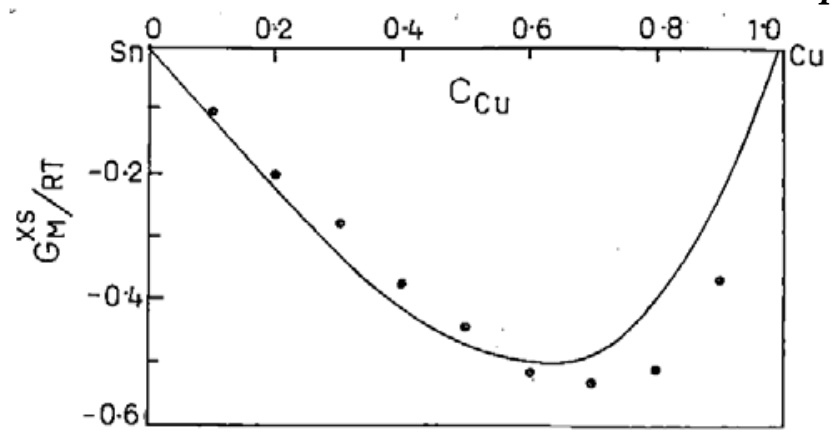

Fig (1) - $\mathrm{G}_{\mathrm{M}} / \mathrm{RT}$ vs $\mathrm{C}_{\mathrm{cu}}$ for $\mathrm{C}_{\mathrm{u}} \mathrm{S}_{\mathrm{n}}$ liquid alloys at $1400^{\circ} \ldots$. . Theory (...) experiment ( )

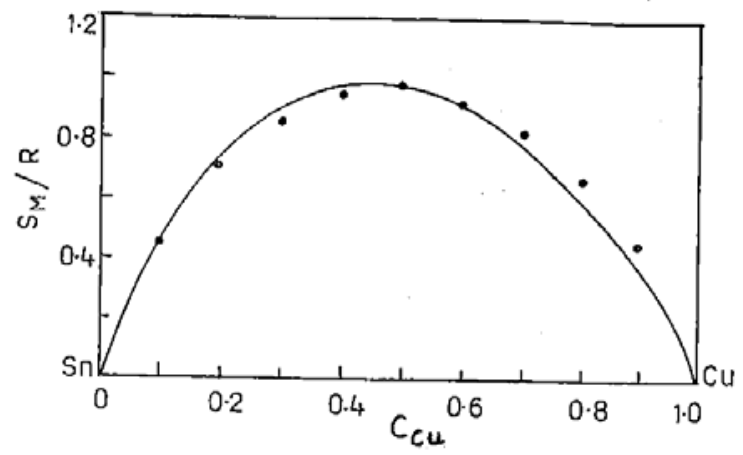

Fig (2) - $\frac{\mathrm{H}_{\mathrm{M}}}{\mathrm{RT}}$ vs $\mathrm{C}_{\mathrm{cu}}$ for $\mathrm{C}_{\mathrm{u}} \mathrm{S}_{\mathrm{n}}$ liquid alloys at $1400^{\circ} \mathrm{K}$.....theory ; (...) : experiment ( Hultgren et al 1973).

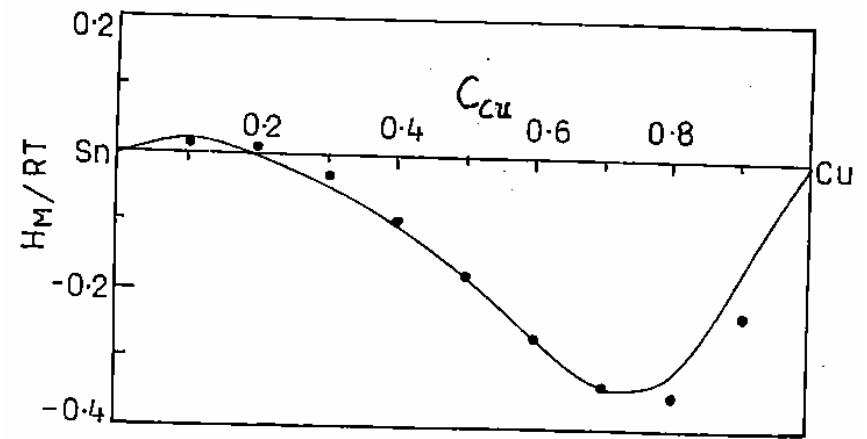

Fig (3) - $\frac{S_{M}}{R}$ Vs $C_{c u}$ for $C_{u} S_{n}$ liquid alloys at $1400^{\circ} K$.....theory ; (...) : experiment ( Hultgren et al 1973). 